\title{
EFFECTS OF WORK STATUS OF PATIENTS WITH CHRONIC LOW BACK PAIN ON PHYSICAL AND MENTAL HEALTH AND FUNCTIONAL LIMITATION
}

\begin{abstract}
BACKGROUND: Concern about the decision of whether or not to continue to work with symptoms of back pain and the impacts of such decision on the general health of patients with low back pain has not been widely investigated. OBJECTIVES: The purpose of this study was to investigate the effects of work status of patients with chronic low back pain on physical and mental health and functional limitation
\end{abstract}

METHODS: 160 participants with chronic low back pain [CLBP] participated in this study. CLBP participants work status was categorised into 3 groups; completely off work, working with restrictions and completely at work. Rand 36 questionnaire was used to assess bodily pain, physical health and mental health. Rolland Morris disability questionnaire was used to assess functional limitation due to low back pain. Analysis of Variance (ANOVA) was used to compare bodily pain, physical health, mental health and functional limitation among the 3 groups. A post hoc analysis [LSD] test was carried out where ANOVA showed significant difference. Level of significance was set at 0.05 .

RESULTS: CLBP patients who are completely off work, working with restrictions and completely at work recorded a mean score of $42.7 \pm 14.19,92.13 \pm 36.6$ and $111.13 \pm 46.3$ respectively for bodily pain. CLBP patients completely off work has a mean functional limitation score of $13.11 \pm 5.65$ while those completely at work has $6.83 \pm 4.40$ and those working with restrictions measured $10.92 \pm 4.46$. Physical health scores of $197.2 \pm 19.59,356.7 \pm 24.88$ and $383.96 \pm 85.6$ for CLBP patients who are completely off work, working with restrictions and completely at work respectively. ANOVA test showed significant difference in the bodily pain, functional limitation and physical health scores among the three groups $(P<0.05)$. Completely at work and completely off work group recorded mean score of $343.8 \pm 85.6,328.8 \pm 85.5$ respectively while the working with restriction group recorded a score $353.0 \pm 85.3$ for mental health. ANOVA test did not show a statistical significant difference in the mental health scores among the 3 groups $(F=0.661, P=0.518)$

CONCLUSION: Findings from this study has shown that CLBP patients who are either completely at work or working with restrictions experienced less bodily pain, reduced functional limitation and better physical health than those who are completely off work

KEY WORDS: BACK PAIN, ERGONOMICS, FUNCTIONAL LIMITATION, MENTAL HEALTH, PHYSICAL HEALTH AND WORK STATUS.

\section{INTRODUCTION}

Low back pain is an important public health, social and economic problem. It is also a disorder with many possible aetiologies occurring in different groups and is also a common health problem in working population. It has been estimated that up to $60-80 \%$ of population will at some point in their lives experience back pain [Cassidy et al., 2005]. Back pain leads to high cost for the individual, the work place and the society and it is one of the most cited causes of sickness absence [Hansson and Hansson 2005]. Musculoskeletal disorders especially CLBP are a major cause of disability in the working population. Concern about continuing to work with symptoms of back pain is often expressed by CLBP patients themselves, primary care health professionals and occupational health professionals, as well as supervisors and management at work place, particularly if the CLBP is attributed to work and if there is thought to be a risk of re-injury. A recent study has highlighted the variability in physician advice on continuing to work and return to work and that recommendations often reflect personal attitudes of the physicians and their perception of the severity of symp-

\section{Corresponding Author}

Department of Medical Rehabilitation College of Medical Sciences

University of Maiduguri PMB 1069 Maiduguri, Nigeria e-mail:ganiyusokunbi@gmail.com 
toms [Rainville et al., 2000] rather than empirical evidence on the effects of work status on the health of patients with low back pain. Low back pain [LBP] is commonly a persistent or recurrent problem, and it is possible that most workers do continue working or return to work with some restrictions while symptoms are still present. Epidemiological and clinical follow-up studies show that early return to work and or working with restrictions with some persisting symptoms does not increase the risk of 'reinjury' but actually reduces recurrences and sickness absence. Conversely, the longer a CLBP patient is off work, the lower the chance of recovery [Rainville et al., 2000]. Undue caution by staying completely off-work could form an obstacle to return to work and lead to protracted sickness absence, which then aggravates and perpetuates chronic pain and disability, and actually increases the risk of a poor long-term outcome [Rainville et al., 2000]. Few studies have been carried out on the impact of low back pain on work related psychosocial factors. Turk and Rudy [1988] identified three groups of chronic pain patients based on work related psychosocial parameters; The first group, "dysfunctional patients", corresponds to patients with high pain severity, a low activity level, marked interference with everyday life due to pain, high affective distress, and low perception of life control. The second group, "adaptive copers", is characterized by a lower pain severity, a

Table 1: Demographic characteristics of the participants

\begin{tabular}{|l|l|c|c|}
\hline \multicolumn{2}{|l|}{ Demographic variables } & N & $\%$ \\
\hline \multirow{4}{*}{ Age (\%) } & 15-24 years & 11 & 6.9 \\
& 25-34years & 23 & 14.4 \\
& 35-44years & 45 & 28.1 \\
& 45-54years & 58 & 36.2 \\
& 55years and above & 23 & 14.4 \\
\hline \multirow{5}{*}{ Marital Status } & Single & 22 & 13.8 \\
& Married & 137 & 85.6 \\
& Divorced & 0 & 0 \\
\hline \multirow{3}{*}{ Gender } & Separated & 80 & 50 \\
& & 80 & 50 \\
& Male & & \\
\hline
\end{tabular}

higher activity level, lower interference and affective distress, and higher life control. The third group, "interpersonally distressed", features middle pain severity, general activity, interference and affective distress, and lower social support than the other two groups. In a similar vein, Shaw et al., [2007] identified four groups of patients with acute work-related back pain based on disability risk factors; Group one consists of patients who are most affected by pain and concern with high physical demands at work. This group resembles the "fear avoidance" category and shows low expectations of returning to work. Group two is characterized by a high rate of emotional distress, impaired mental health and above average pain intensity. Patients in group three are identified by a high degree of concern about job placement. Finally, patients from group four show low risk factors for disability. They have positive expectations for workplace accommodation and returning to normal work. Even though the included variables and patient populations of the aforementioned studies differ, they all have one aspect in common: A patient group with low back pain with impaired mental and physical health at varying degree of pain severity and with concerned about remaining at and/or returning to work. Thus, the present study aimed to investigate the effects of work status of chronic low back pain patients on physical and mental health and functional limitations due to low back pain.

\section{METHODS}

Design: Information on health status and functional limitation from a cross section of population of patients with chronic low back pain [Cross sectional study] was collected and analysed in this study.

Aim: This study was aimed at investigating whether CLBP patients who are either completely at work or working with restrictions will experience different levels of bodily pain, functional limitation and health status from those who are completely off work.

Objectives: The Purpose of this study was to investigate the effects of work status of patients with chronic low back pain on physical and mental health and functional limitation.

Ethics: Approval to carry out this study was obtained from the Research and Ethics Committee of the University of Maiduguri Teaching Hospital, Maiduguri. Detailed information on what the study was and what was expected of the participants was provided in participant's information sheet. Participants were required to sign the written informed consent, and they were given enough time to decide whether they will take part in this study.

Recruitment Strategies: Participants were recruited from among patients with chronic low back pain from Orthopaedic and Medical outpatient's clinics of the University of Maiduguri Teaching Hospital, Maiduguri and State Specialist Hospitals in Maiduguri, Borno State. Prior to this, printed recruitment posters and handbills were distributed to prospective participants in the outpatient clinics of these hospitals. Recruitment posters were also displayed on notice boards at strategic areas within these hospitals.

Participants: Purposive sample of 160 Patients with nonspecific low back pain [NSLBP] of mechanical origin, of at least 1 year duration and aged 18 to 65 years participated in this study. Patient with low back pain caused by other factor such as cancer, tuberculosis, tumour and other serious spinal pathological conditions were excluded from this study.

Procedures: One hundred and sixty questionnaires were administered by hand to the participants who were also 
Table 2: Effects of work status on bodily Pain scores, functional limitation, physical health and mental health scores of participants

\begin{tabular}{|l|c|c|c|c|c|}
\hline & $\begin{array}{l}\text { Completely off } \\
\text { work }\end{array}$ & $\begin{array}{l}\text { Working with } \\
\text { restrictions }\end{array}$ & $\begin{array}{l}\text { Completely at } \\
\text { work }\end{array}$ & F values & P values \\
\hline Bodily pain scores & $42.7 \pm 14.19$ & $92.13 \pm 36.6$ & $111.13 \pm 46.3$ & 2.833 & $0.03^{*}$ \\
\hline $\begin{array}{l}\text { Physical Health scores } \\
\text { Mental Health scores }\end{array}$ & $197.2 \pm 19.59$ & $356.7 \pm 24.88$ & $383.96 \pm 85.6$ & 0.795 & $0.04 *$ \\
\hline $\begin{array}{l}\text { Functional Limitation } \\
\text { (RMDQ) scores }\end{array}$ & $13.11 \pm 5.65$ & $10.92 \pm$ & $6.83 \pm 4.40$ & 0.661 & 0.518 \\
\hline
\end{tabular}

required to complete and returned within 24hours. Information on sociodemographic characteristics, work status, functional limitation due to low back pain, physical health and mental health of patients with chronic low back pain were collected with a well-structured questionnaires. For the purpose of this study participants work status could either be; currently working, working with restrictions or not currently working. Completely at work implies working for a period of time i.e.at least 6 months of employment prior to this present study while working with restrictions implies working for the same period of time but with reduced working hours and or doing less heavy jobs. Participants who are completely off work are those who have completely given up their job, for the same period of time because of the problem of chronic low back pain [Kuijer et al., 2006].

Roland Morris Disability Questionnaire (RMDQ) was used to assess functional limitation due to LBP. In patient with chronic low back pain, a correlation coefficients of 0.72 with interclass correlation coefficient which range from $0.42-0.53$ has been reported for the use of RMDQ [Smith and GrimmerSomers 2010]. CLBP Quality of life [QoL] is typically assess in 5 domains; function, work disability, pain, satisfaction and general health. RMDQ assess the functional domain of chronic low back pain QoL[Roland and Morris 1983].
The Rand -36 questionnaire was used to assess bodily pain, physical health and mental health of participants with low back pain. It contains 36 items, which are identical to the MOS SF-36, with the scoring of items on Rand 36 questionnaire, a high score indicates an excellent (positive) outcome while a low score indicates a poor (negative) outcome. Rand 36 has been reported to be a reliable outcome measure to assess bodily pain, physical mental health variables and quality of life [Ware and Sherborne 1992].

Data analysis: Effect of work status on physical health, mental health and functional limitation among the 3 groups were carried out using analysis of variance (ANOVA) and a post hoc analysis was carried out with LSD test whenever statistical significant difference was found. The statistical significant was set at $\mathrm{P}<0.05$

\section{RESULTS}

One hundred and sixty questionnaires were completed and returned within a period of 12 months from the administration of the first questionnaire, giving a response rate of $100 \%$. All the returned questionnaires were included in the analysis process

\section{Participants' Demographic variables}

Demographic variables of the participants are presented in Table 1. One hundred and three [64.3\%] of the par- ticipants were aged between 35 and 54 years. Thirty Four participants [21.3\%] were within the age of 15-34 years while the remaining 33 participants [14.4\%] were 55 years old and above.

\section{Effects of work status on bodily pain}

Table 2 showed the mean score for bodily pain, functional limitation, physical health and mental health scores of participants using Rand 36 questionnaire. Participants with CLBP who are completely off work, working with restrictions and completely at work recorded a mean score of $42.7 \pm 14.19,92.13$ \pm 36.6 and $111.13 \pm 46.3$ respectively for bodily pain domain. One way Analysis of Variance [ANOVA] showed statistical significant difference in the bodily pain scores among the three groups $[\mathrm{F}$ $=2.833, \mathrm{P}=0.03]$. The post hoc analysis with LSD test showed statistical significant difference in bodily pain scores between each of the following pairs; 'completely off work' and 'working with restrictions' ( $\mathrm{P}=0.048)$, 'completely off work' and 'completely at work' [P $=0.045]$, and 'working with restrictions and completely at work' $[\mathrm{P}=0.022]$ [Table 3].

\section{Effects of work status on functional limitation}

Table 2 showed that the mean cores for functional limitation due to low back pain measured with Roland Morris 
Disability Questionnaire. The completely off work participants have the highest mean functional limitation score $[13.11 \pm 5.65]$ while the completely at work participants have the least mean functional limitation score [6.83 \pm 4.40$]$. ANOVA test showed statistical significance difference in the functional limitation scores among the three groups $[\mathrm{F}=1.988, \mathrm{P}=0.014]$. Table 3 showed the results of the post hoc analysis on functional limitation scores. It showed statistical significant difference between 'completely at work' and 'completely off work' $[\mathrm{P}=0.00]$. However the 'completely at work' and 'working with restrictions' did not show statistically significant difference [ $\mathrm{P}>0.05]$.

\section{Effects of work status on physical health}

Table 2 showed that the mean scores recorded in the physical health domain of Rand 36 questionnaire were 197.2 $\pm 19.59,356.7 \pm 24.88$ and $383.96 \pm 85.6$ for the completely off work, working with restrictions and completely at work respectively. ANOVA test showed statistical significant difference in physical health's scores among the 3 groups $[F=0.795, P=0.04]$. Table 3 showed the LSD post hoc analysis test on the effect of work status on physical health scores. The results showed statically significant difference in the physical health scores between each of the following pairs; 'completely at work' and 'completely off work' $[\mathrm{P}=0.04]$, and 'working with restrictions' and 'completely off work' $[\mathrm{P}=0.00]$.

\section{Effects of work status on mental health}

Table 2 showed that the mean scores recorded in the mental health domain of Rand 36 questionnaire. Completely off work group recorded the least mean score of $328.8 \pm 85.5$ while the working with restriction group recorded the highest score of 353.0 \pm 85.3. ANOVA test did not showed statistical significant difference in the mental health scores among the 3 groups $[\mathrm{F}=0.661, \mathrm{P}=0.518]$

\section{DISCUSSION}

The outcome of this study showed that participants with low back pain and who are still actively at work recorded less effect of bodily pain, better physical health and less effects of functional limitation due to low back pain compared to either the participants who were completely off work or those who are working with some restrictions. Although there appeared to be little evidence on the relationship between work status and measures of disability, pain or health among patients with low back pain, in

Table 3 Post -hoc analysis of the effects of work status on pain intensity, functional limitation and Physical health scores

\begin{tabular}{|l|l|}
\hline Work Status & P-Values \\
\hline Pain Intensity & \\
Completely at work Vs Working with restrictions & $0.022^{*}$ \\
Completely at work Vs completely off work & $0.045^{*}$ \\
Working with Restrictions Vs Completely off work & $0.048^{*}$ \\
\hline Functional limitation & \\
Completely at work Vs Working with restrictions & \\
Completely at work Vs completely off work & 0.906 \\
Working with Restrictions Vs Completely off work & $0.00^{*}$ \\
& 0.06 \\
\hline Physical Health & \\
Completely at work Vs Working with restrictions & 0.537 \\
Completely at work Vs completely off work & $0.04^{*}$ \\
Working with Restrictions Vs Completely off work & $0.00^{*}$ \\
\hline
\end{tabular}

the results of the present study it could be that an emphasis on being active at work [completely at work] could be a prime strategy to curtail the menace of acute and chronic low back pain [LBP] reduction in bodily pain. It could also improve functional limitation and physical health status of the individual diagnosed with chronic low back pain.

Effective strategies to manage LBP and prevent recurrence and chronicity still remain elusive [Arnau et al., 2006; Kent and Keaton 2008], however, there is an increasing focus to create strategies for preventing the negative consequences of chronic LBP on the health status of people who suffer with it [Majeed and Trummees 2008]. A recent review found evidence supporting the use of advice to remain active at work as a key element of active self-management in chronic LBP populations [Liddle et al., 2007]. While graded activity programmes have been trialled as a management strategy for acute and chronic LBP populations [Steenstra et al 2006]. The results of the present study in terms of reduced impairments such as bodily pain and functional limitation in participants who are completely at work and those who are working with some restrictions agree with the findings from previous studies. Hurwitz et al., [2005] reported a statistically significant relationship whereby lower levels of activity were inversely associated with pain and LBP-related disability. However, the study conducted by Hurwitz et al involved recreational activities and it is not clear whether their findings could be directly related to a different environment i.e. a work environment, as investigated in the present study.

The reduction in functional limitation and bodily pain observed in patients with CLBP who are either completely at work or at least working with some restrictions could be partly explained using the deconditioning model of LBP [Wittink et al., 2000]. This model is supported by evidence of positive associations of reduced levels of activity of patients with LBP with various changes such as reduced physical functioning, impaired neuromuscular changes, negative psychological effects, and decreases in physical fitness. Low back pain, which precipitates decreased activity 


\section{World Confederation for Physical Therapy}
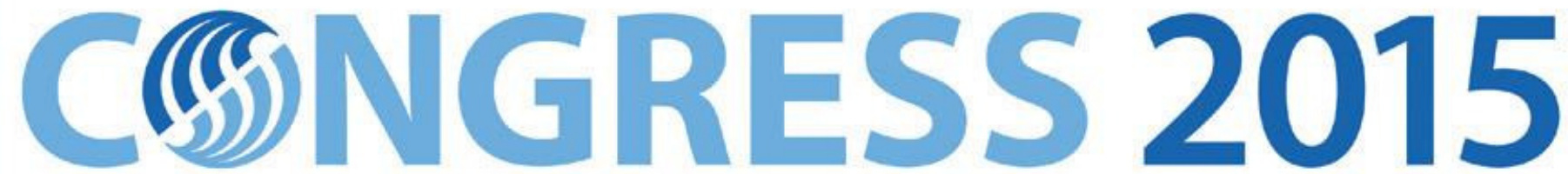

Singapore

1-4 May 2015

Preliminary
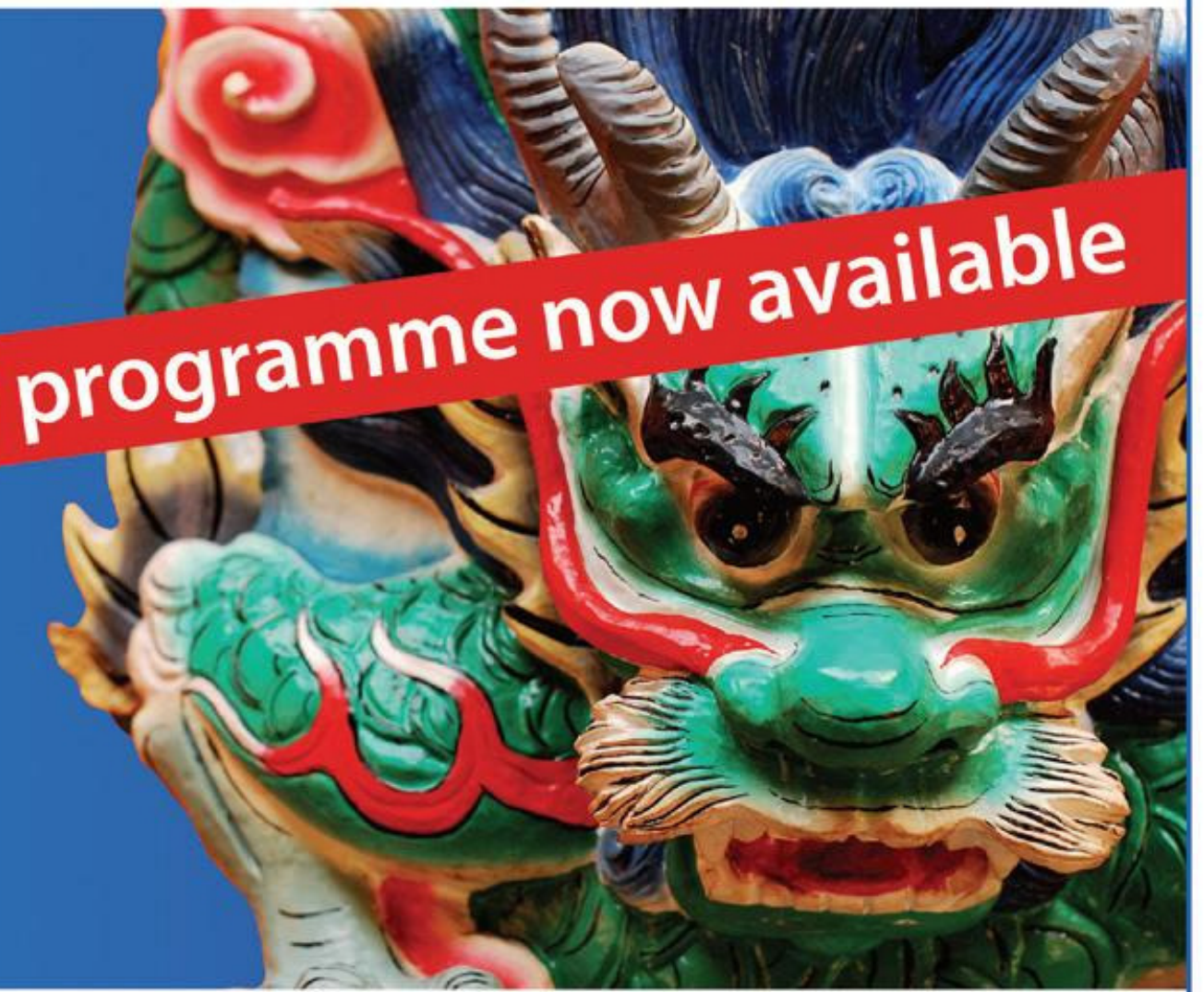

Where the world of physical therapy meets Advance registration, at reduced rates is open until 31st March 2015.

There are also special rates for members of WCPT member organisations, retired physical therapists, students and PT assistants.

View all registration fees and deadlines online.

www.wcpt.org/congress

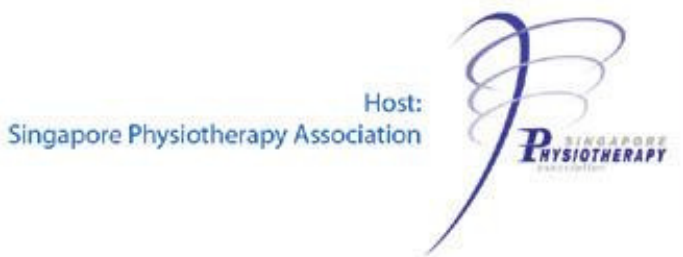

\section{(S(J)) World Confederation}


and fear avoidance beliefs, may lead to a decline in conditioning. Therefore, it could be possible that, for patients with low back pain, being completely at work could be one of the ways of curtailing and/or preventing the menace of physical inactivity, deconditioning and ultimately improving their health status. Hurwitz et al., [2005] reported that staying at work could also produce other benefits for CLBP patients, including, higher pain threshold, positive effects on mood, anxiety, and depression, which often plague these patients. Heneweer et al., [2009] reported a U-shaped relationship in that both high and low levels of activity increased the likelihood of an increasing pain and functional limitation and report of LBP chronicity, particularly in females. Their findings could potentially generate a question of what level of work activity will be advisable to ensure favourable outcome in terms of reduction in pain severity and functional limitation among patients with low back pain who are still currently working either with or without preventive ergonomic measures such as work restrictions. Mortimer et al., [2006] in their study, specifically stratified activity into low, moderate and high levels and used self-report measures to explore the relationship with LBP outcomes. Their study found no significant relationship between activity levels and changes in pain and disability. Conversely, the results of the present study in terms of reduced bodily pain, less functional limitation and better physical health showed a clear trend in favour of CLBP patients who were completely at work than those working with restrictions. Thus it could be that working with some form of restrictions such as reduced work hours, avoid lifting, bending etc. might help to prevent or reduce the risk of injury among patients with CLBP. It is also possible that certain other factors not yet well investigated could have a role to play in the overall physical and mental health status of workers with low back pain. These factors could range from leadership, work culture, job responsibilities, insurance system, financial insecurity, communications, family and personal life, relationship at work etc. [Ukessays 2013]. If these findings are confirmed, intervention strategies aimed at improving return to work and optimising the health status of workers with low back pain should address multiple dimensions of both the worker and the workplace. Hibert et al., [2003] evaluated the association of prescribed work restrictions with work absenteeism and recurrence in cases of nonspecific low back pain. They reported no association between prescription of work restriction and duration of work disability.

It has become clear that chronic pain is associated with high rates of mental health impairments. The comorbid relationship between chronic pain and these disorders has been identified in patients with chronic low back pain (LBP) and chronic work-related musculoskeletal pain disability [Polatin et al., 1993]. A study reported that $10.6 \%$ to $62.5 \%$ of patients with chronic pain meet current criteria for any anxiety disorder compared with $1 \%$ to $25 \%$ in the general population [Regier et al., 1988]. Keeping active at work tends to improve mood and mental health states and, with decreased need for alternate health care and pain medications [Sculo et al., 2001]. There could be many possible explanations for this, work place could be a possible source of psychosocial support for low back pain workers. [Heitzmann and Kaplan 1984] identified sources of psychological support for people returning to work following a period of illness. They reported that for men psychological support would come first from the spouse, for women psychological support is more likely to be found outside the couple, so there may be more incentives to go back to work. Specifically such incentives could come from the employers by addressing specific work related factors the employee feels have contributed to their illness, making reasonable adjustment to deal with the stress and psychological demands of the role of the employee, writing up a good return to work plan which will include the nature of duty and hours of work to be flexible enough to allow for any changes that may occur during recovery from injury and illnesses. Additionally, an employee experiencing or recovering from depression or anxiety, participation in the workplace can have a significant impact on the person's emotional, social and physical well- being. Even if the employee is on limited hours or duties, positive effects of returning to work on mental health, mood, workers morale and sense of belongings can be enhanced as the worker is able to interact with others, make contribution at work and the worker feels part of the team [WHO 2004].

Anshel and Russell [1994] found that work improved vigor while decreasing fatigue, tension, and depression. However, findings from this present study indicated better mental health status for participants who were either completely at work and or working with restrictions than those who were completely off work, the mental health scores did not show significant difference among the three groups. This perhaps could be partly due to using a self- report questionnaire for the assessment of mental health in the present study. There are many barriers present in accurately diagnosing and assessing severity of mental health and psychosocial distress with self-report questionnaires [Spitzer et al., 1999]. It could be that if standard measures for diagnostic assessment (e.g. the Structured Clinical Interview for Diagnostic and Statistical Manual of Mental Disorders [DSM] [SCID] etc.) were used these results might be different.

Overall, the result of the present study is similar to studies internationally on the topic of LBP and the return to work. However in Africa the results of our study contributes to the current body of knowledge. Soaker et al., [2008] carried out a semi-structured focus group interview to elicit perceptions and experiences of facilitators and barriers that affected individuals who received back rehabilitation and their ability to resume their workers roles. The outcome of their study showed that a positive work culture and having meaningful work experiences as facilitators while physical and psychosocial stressors of the job a lack of education by the employer and inadequate workplace policy were reported as barriers factors. Self-efficacy and being aware of and utilizing own choice of medication were identified as some of the methods of adaptation to the worker's role after back rehabilitation In a follow up study carried out by Soaker 
et al.,[2009]. It could be that the findings from the present study would have been further enhanced by carrying out a qualitative study in the form of focus group interview to elicit the experiences of the participants on the impact of their returning to work on their physical and mental health status.

\section{CONCLUSION}

Findings from this study showed that CLBP patients who were either completely at work or working with restrictions experienced less bodily pain, reduced functional limitation and better physical health than those who are completely off work.

\section{IMPLICATIONS FOR PRACTICE}

Chronic low back pain is not simply a physical problem. It is often associated with impaired physical and psychological wellbeing factors. Many of these factors interact, and the whole picture needs to be considered when managing individual patients. Treatment should not just be aimed at pain relief, intervention strategies should aimed at improving return to work as a means of addressing multiple dimensions of pain, functional limitation impaired physical and mental health wellbeing. Physiotherapists have an important role to play in this process including providing initial assessment, effective early treatment, facilitating participatory ergonomics via good communication between CLBP patient and all involved parties to develop suitable return to work plan and providing ongoing monitoring [Ammendolia et al., 2009; Fenner 2013]. A return to work plan that enables the injured worker to perform most of their usual tasks keeps them 'work hardened' while protecting the injury by specifying appropriate restrictions on tasks, or parts of a task that may aggravate the injury. To facilitate the rehabilitation process, communication is essential between the therapist, other care givers and the employer regarding the condition, expected investigation and treatment processes, a suitable duties plan and the likely timeframe for a return to full duties. Advise on weight or lifting restrictions, movements to avoid, and time restrictions for particular tasks, including how tasks can slowly be increased within pain and/ or mobility restrictions may be useful. Modified duties, work hours and/or days per week may also need reducing. For example, work hours may be reduced to 2-4 hours per day with working days alternating with a rest day between. The hours can then be gradually increased to 6,8 and then 12 hours if this is the normal working day, as the worker improves. This approach maintains work fitness and increases work hardening. When a worker can cope with a full day's work, then the number of days per week (or shifts) is increased, although the work tasks may still be restricted during this time.

\section{LIMITATION}

The present study did not take into account the impact of recurrence of back pain on the self-report functional limitation, physical health and mental health status of the participants. It could be that workers with low back pain who experience recurrence after return to work might have more health problems and work limitations than those who did not experience recurrence of symptoms and their health status might be comparable to those who do not return to work. Thus, future research should further explore the relationship between recurrence(s) of back pain, health status, and work limitations over an extended period of time. A mixed method study design incorporating cross sectional observational survey and focus group interview on the impact of work status on the participants' perceived level of functional limitation and health status could have provided enriched information on the participant's experience of the physical and mental health to compliment the information obtained from the use of self-reported questionnaires.

\section{REFERENCES}

Ammendolia C, Cassidy D, Steenstra I, Soklaridis S, Boyle E, Eng S, Howard H, Bhupinder B, and Côté P, 2009. Designing a workplace return-to-work program for occupational low back pain: an intervention mapping approach. BMC Musculoskeletal Disorders 10(65):1471-1474

Anshel MH, Russell KG 1994 . Effect of aerobic and strength training on pain tolerance, pain appraisal and mood of unfit males as a function of pain location. $J$ Sports Sci. 12:535-547.

Arnau JM, Vallano A, Lopez A, Pellise F, Delgado MJ, Prat N; 2006. A critical review of guidelines for low back pain treatment. Eur Spine J. ; 15:543-553.

Cassidy JD, Cote P, Caroll LJ 2005. Incidence and cause of low back pain episodes in the general population. Spine; $24 ; 2817-23$

Essays, UK. 2013. Internal and External Factors Affecting Organisational Behaviour Business Essay. Retrieved from http://www.ukessays.com/essays/ business/internal-and-external-factors-affectingorganisational-behaviour-business-essay

Fenner, P. 2013 Returning to work after an injury. Workplace: 182-185

Hansson EK, Hansson TH 2005. The cost for person sick listed more than one month because of low back or neck pain problem a two year prospective study of sweedish patients. Europ Spin J;14;337-345

Heitzmann CA, Kaplan RM. 1984. Interaction between sex and social support in the control of type II diabetes mellitus. J Consult Clin Psychol.;52:1087-1089

Heneweer H, Vanhees L, Picavet HSJ 2009. Physical activity and low back pain: a U-shaped relation? Pain; 143:21-25.

Hiebert R, Skovron ML, Nordin M, Crane M 2003. Work restrictions and outcome of nonspecific low back pain Spine 1;28(7):722-8.

Hurwitz EL, Morgenstern H, Chiao C. 2005; Effects of recreational physical activity and back exercises on low back pain and psychological distress: findings from the UCLA Low Back Pain Study. Am J Public Health. ;95:1817-1824.

Kent PM, Keating JL. 2008 Can we predict poor recovery from recent-onset nonspecific low back pain? A systematic review. Man Ther. 13:12-28

Kerns R, Turk D, Rudy T 1985: The West HavenYale multidimensional pain inventory (WHYMPI). Pain, 23:345-356

Kuijer W, Brouwer S, Preuper R, Johan W. Groothoff Jan H.B. Geertzen Pieter U, 2006 Work status and chronic low back pain Exploring the International Classification of Functioning, Disability and Health; Disability and Rehabilitation, ; 28 (6): 379-388

Liddle SD, Gracey JH, Baxter GD 2007. Advice for the management of low back pain: a systematic review of randomised controlled trials. Man Ther. ;12:310-327 
Majid K, Truumees E 2008. Epidemiology and natural history of low back pain. Semin Spine Surg. ;20:87-92

Mortimer M, Pernold G, Wiktorin C 2006. Low back pain in a general population. Natural course and influence of physical exercise - a 5-year follow-up of the Musculoskeletal Intervention Center-Norrtalje Study. Spine.;31:3045-3051

Polatin PB, Kinney RK, Gatchel RJ, Lillo E, Mayer TG 1993. Psychiatric illness and chronic low-back pain. The mind and the spine-which goes first? Spine;18(1):66-67

Rainville J, Carlson N, Polatin P, Gatchel RJ, Indahl A. 2000. Exploration of physicians' recommendations for activities in chronic low back pain. Spine; 25:2210-2219

Regier DA, Boyd JH, Burke JD, 1988. One-month prevalence of mental disorders in the United States. Arch Gen Psychiatry;45(11):977-986.

Roland M, Morris R. A 1983 study of the natural history of back pain. Part I: development of a reliable and sensitive measure of disability in low-back pain. Spine ;8:141-144.
Sculco AD, Paup DC, Fernhall B, Sculco MJ 2001. Effects of aerobic exercise on low back pain patients in treatment. Spine J.;1:95-101

Shaw WS, Pransky G, Patterson W, Linton SJ, Winters T 2007: Patient clusters in acute, workrelated back pain based on patterns of disability risk factors. J Occup Environ Med, 49:185-193

Smith C, Grimmer-Somers K. 2010. "The treatment effect of exercise programmes for chronic low back pain”. J Eval Clin Pract 16, 484-91

Soeker MS, Wegner L, Pretorius B. 2008. I am going back to work back injured clients' perceptions and experiences of their work roles Work 30(2) 161-70

Soeker MS, Wegner L, Pretorius B. 2009, South African clients' perception and experiences of adapting to their work roles after rehabilitation. Work 32(2):133-143

Spitzer RL, Kroenke K, Williams JB 1999. Validation and utility of a self-report version of PRIME-MD: the PHQ primary care study. Primary Care Evaluation of Mental Disorders. Patient Health Questionnaire. JAMA.;282(18):1737-1744
Steenstra IA, Anema JR, Bongers PM, Vet HC, Knol DL, Mechelen W 2006. The effectiveness of graded activity for low back pain in occupational healthcare. Occup Environ Med.; 63:718-725

Turk DC, Rudy TE 1988: Toward an empirically derived taxonomy of chronic pain patients: integration of psychological assessment data. J Consult Clin Psychol, 56:233-238

Ware. J.E., and Sherbourne.C.D. 1992:" The Medical Outcome Study (MOS) 36-Item Short-Form Health Survey (SF-36): I Conceptual Framework and Item Selecting, Medical Care.30, 473-

World Health Organisation (2004). Work organisation and stress.Protecting Workers' Health Series Number 3

Wittink H, Hoskins Michel T, Wagner A, Sukiennik A, Rogers W. Deconditioning in patients with chronic low back pain: fact or fiction? Spine. 2000;25:22212228

\section{GET HEALTHIER}

Ergotherapy Solutions now offers physiotherapists a solution for patients that require complete support in a work chair.

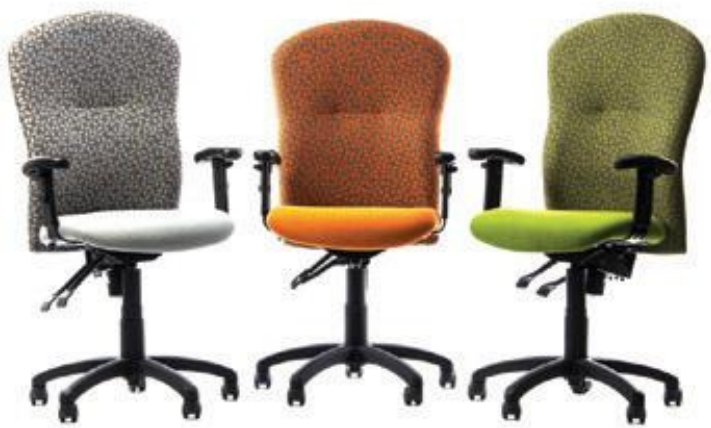

The GET ONETM midback

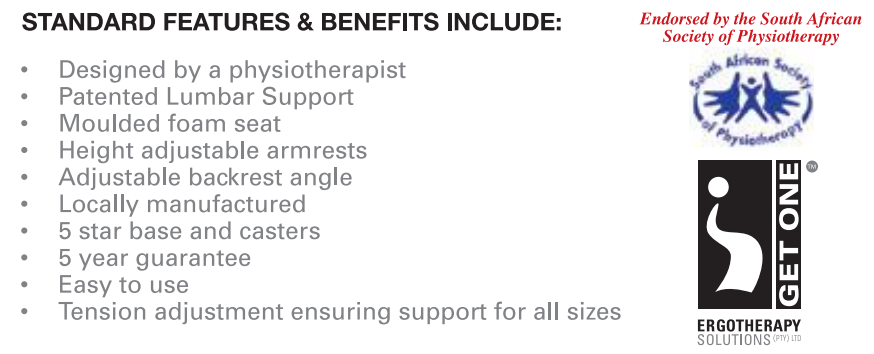

Call us to arrange a visit and info pack

Ergotherapy ${ }^{\mathrm{TM}}$ Solutions

(1)+27 113265126 (1) +27 113265127 (B) info@ergotherapy.co.za

Unit 4, Block A, Upper Grayston Office Park,

150 Linden Road, Sandton

P.O. Box 575, Strathavon, 2031, RSA 